\title{
Health Related Quality of Life Among Heart Failure Patients Attending an Outpatient Clinic at University of Gondar Comprehensive Specialized Hospital Northwest Ethiopia 2020: Structural Equation Modeling Approach
}

Gebrekidan Ewnetu Tarekegn ( $\square$ ewnetuwendale@gmail.com )

Department of Epidemiology and Biostatistics, Institute of Public Health, College of Medicine and Health Sciences, University of Gondar, Gondar, Ethiopia. https://orcid.org/0000-0001-7356-0912

Lemma Derseh Gezie

University of Gondar College of Medicine and Health Sciences

Tilahun Yemanu Birhan

university of Gondar college of medicine and health sciences

Research

Keywords: Health related quality of life, Heart failure, Structural equation model, Ethiopia

Posted Date: August 28th, 2020

DOI: https://doi.org/10.21203/rs.3.rs-60569/v1

License: (9) This work is licensed under a Creative Commons Attribution 4.0 International License. Read Full License 


\section{Abstract}

Background: Chronic heart failure (CHF) is one of the most important public health concerns in the industrialized and developing world having increasing incidence and prevalence. Measuring quality of life using rigorous statistical method may be helpful to provide input for decision makers, policy makers and development of guidelines for the Ethiopia. The aim of this study was to determine health-related quality of life and its associated factors among heart failure patients attending University of Gondar comprehensive specialized hospital.

Methods: A cross-sectional study design was employed to select 469 heart failure patients who has follow up at the University of Gondar comprehensive specialized hospital consecutively from March 1 to 30, 2020. Data were entered to Epi-info7 and exported to STATA 14 and Amos for further analysis. The four Quality of life domains were measured with Standardized World Health Organization Quality of Life BREF. Structural equation modeling was employed to estimate the relationships among exogenous, mediating, and endogenous variables simultaneously.

Results: Chronic heart failure patients had a significant lower mean score in all domains of health-related quality of life ( $p$-value 0.0001 ). Age had a direct positive effect on all domains of health-related quality of life and a positive total effect on overall health related quality of life. Residency also had a direct negative effect on both physical and environmental health related quality of life domain. Duration of chronic heart failure had a direct negative effect on psychological health. There was strong correlation among the four domains of health-related quality of life.

\section{Conclusion}

Poor health related quality of life in the physical dimension, moderately poor overall health related quality of life and a moderate health related quality of life in the psychological health domain. Developing and providing intervention programs to enhance social support can lead to improved quality of life for patients, because of the long-term and chronic illness of the patient.

\section{Background}

Heart failure is a global public health problem that affects more than 26 million people worldwide and 550,000 new cases are diagnosed each year $(1,2)$. Heart failure is a serious condition, and usually there's no cure. But many people with heart failure lead a full, enjoyable life when the condition is managed with heart failure medications and healthy lifestyle changes (3).

World health organization defines quality of life as "individual's perception of their position in life in the context of the culture and value systems in which they live and in relation to their goals, expectations, standards and concerns." It is a broad ranging concept affected in a complex way by the person's physical health, psychological state, social relationships, and their relationship to salient features of the environment (4). 
World Health Statistics in 2012 showed that CHF has created an economic burden of 180 million dollars in the health system (5). Different physical and mental complications such as fatigue, depression, anxiety, edema, shortness of breath due to the chronic and prolonged disease course, and therapeutic processes have a serious and negative impact on the health related quality of life (HRQOL) $(5,6)$. Lower HRQOLs correlate with increased hospitalization occupancy and mortality rates, and higher costs imposed on health systems, families, and patients (7-9).

Health-related quality of life is influenced by numerous physical, emotional, and social factors and uniquely perceived by each individual. The structured assessment of HRQOL is considered important in promoting patient centric care. It puts the patient's perspective at the forefront and can identify areas of specific need. This helps to facilitate shared decision-making and ensure that the preferences of the patient are used to guide management (4).

The assessment of symptoms and functional status, using the New York Heart Association (NYHA) classification, is a standard practice in the care of heart failure patients. It is recommended in guidelines as a measure of heart failure severity and is integrated into treatment decision algorithms, despite its shortcomings in reproducibility (10-12). The use of validated instruments to assess HRQOL remains largely limited to clinical trials, with minimal guidance on the practical assessment of HRQOL outside of this setting $(13,14)$.

Maximizing HRQOL among treating CHF is still a major challenge (15-18). In primary care, CHF patients are in need of new concepts adapted to the severity of their disease that consider life expectancy and HRQOL. Patients with CHF mostly experience symptoms such as dyspnea, fatigue, sleep disorders, and ankle edema (19).

Health-related quality of life is a broad and multidimensional concept that subjectively evaluates the physical, psychological, and social health status of individuals and influenced by their understanding, experiences and expectations (20), but most of previous studies on health-related quality of life were considering as observed variable but HRQOL is a multidimensional concept that is better evaluated by a number of latent constructs.

Measuring HRQOL will help in monitoring treatment guidelines and improving patients' HRQOL. Analysis of HRQOL can identify groups with poor HRQOL, and this could guide interventions that will improve their situation and avert more serious consequences, allocate limited resources based on unmet need, guide strategic plan, and monitor the intervention given. More over limited studies were conducted on healthrelated quality of life among heart failure patients in Africa specifically in Ethiopia.

In response to these identified gaps, we conducted a study based on sufficient sample size with appropriate statistical analysis (multivariate statistical analysis). The main objectives of the study were (a) to determine health-related quality of life and associated factors among heart failure patients, and (b) to examine the association among socio-demographic and economic, clinical related variables, and 
among the domain of HRQOL variables. To account for the interdependency of various factors and health related variables, structural equation modeling was employed.

\section{Methods}

\section{Study setting and period}

An institution based Cross-sectional study was employed in University of Gondar comprehensive specialized hospital (UoGCSH) to take a snapshot of population of adult heart failure patients from March 01 to 30/2020. The Gondar city is $727 \mathrm{~km}$ North West of capital city of the country, Addis Ababa. UoGCSH is located the center of Gondar city. Currently, the hospital has a catchment population about 7 million serving as a referral hospital for nearby hospitals. The hospital runs several medical outpatient services including heart failure follow up clinic.

\section{Population}

Patients diagnosed with CHF who had follow up for at least 6 month and age greater than 18 years who visit UoGCSH during the study period were selected as study participants. Patients were excluded from the study if they experienced a concurrent diagnosis of other life-threatening diseases (e.g., cancer), or a chronic severe psychiatric condition (e.g., psychosis).

\section{Sample size determination}

A general rule of thumb is that the minimum sample size should not be less than $\frac{K(K+1)}{2}$ where $k$ is number of observed variables (22). According to the foregoing rule, the minimum sample required were 465 since we have 30 observed variables.

\section{Sampling technique and procedures}

Most of patients in the follow up clinic have one follow up per each month, and the required sample was taken by enumerating all patients during the study period consecutively until the required sample size was secured. In the case of patients who had more than one follow up appointments during the data collection period, their appointment dates were checked and they were excluded from the study.

\section{Variables and measurement}

Data were collected with face to face interview using structured questionnaires. The questionnaire consists of socio-demographic characteristics, clinical related questions and the WHO-QOL tool. Data related to underlying causes of HF and medication regimen were obtained by reviewing the chart, and variables like age, sex, duration of disease, marital status, educational status, occupation, monthly income, enrolment in community-based health insurance and lastly all 26 item variables were obtained by interviewer administered face to face interview. 
The Health related quality measurement domain questionnaire was adopted from WHOQOL which is also validated in Ethiopia and other part of the countries in the world (23). It has 4 domains that denote an individual's perception of quality of life in each particular domain. The WHOQOL-BREF is a 26-item instrument consisting of four domains: physical health domain (7 items), psychological health domain (6 items), social relationships domain (3 items), and environmental health domain (8 items); it also contains the overall perception of QOL and general health (2 items).

Initially questionnaire was prepared in English version, then translated into Amharic (local language) and translated back in to English by another person to check the consistence.

\section{Data processing, model building, and analysis}

The filled questionnaires were checked manually for completeness. Data were coded and entered into EpiInfo version 7 statistical packages and then exported to STATA version 14 and Amos version 25 for further analysis. Descriptive and summary statistics were done using figures and tables. Reliability was also be assessed for each domain of WHO-QoL - Brief using the Cronbach's a coefficient and values of 0.7 or higher were considered satisfactory. The score of each domain of WHO-QOL -Brief was obtained by averaging their corresponding items for each participant. Then the scores were transformed linearly to a $0-100$-scale as described by author(4)

The Structural Equation Modeling (SEM) was employed to examine the relationship between various exogenous and endogenous or mediating variables. Because HRQOL and its domain were latent variables which constitute items with ordered responses, their measurement model was analyzed using SEM because multivariate normality assumption was satisfied after the items parceling (24). The analysis was started with the hypothesized model (Fig. 1), and modifications were performed iteratively by adding path links or including mediator variables, if theoretically supported, and comparing the Root Mean Square Error of Approximation (RMSEA), Comparative Fit Index (CFI) of each model fitted. Finally, an over identified model with value RMSEA $<0.05$ and $\mathrm{CFI}>=0.95$ was retained. Diagrammatically, the effect of each exogenous or mediating variable on the respective dependent variable was indicated by the path coefficient along with single headed arrow, and the correlation among disturbances (residual errors that reflect the unexplained variances in the latent endogenous variables due to all unmeasured causes) was indicated by double arrows. When mediation of effects was present, the direct, indirect, and total effects were determined using the nonlinear combination of estimator technique.

The final model (Fig. 5) that fitted the data well and appeared theoretically meaningful was built by analyzing the hypothesized model (Fig. 1) and inspecting iteratively the statistical significance of path coefficients and the relevance of relationships in the model.

\section{Results}

\section{Socio-demographical characteristics}


From the total, 469 respondents with CHF were enrolled in the study, of whom 316 (67.40\%) were women, $302(64.2 \%)$ were married, 249(53\%) cannot read and write and $108(38.4 \%)$ are housewife in occupation. The mean age of patients was 53 (18.88 SD) years (Table 1).

Table 1

Socio-demographic Characteristics of patients

\begin{tabular}{|c|c|c|c|}
\hline Variables & Categories & Frequency $(N=469)$ & Percept (\%) \\
\hline \multirow[t]{2}{*}{ Sex } & Male & 153 & 32.60 \\
\hline & Female & 316 & 67.4 \\
\hline \multirow[t]{2}{*}{ Residency } & Urban & 255 & 54.4 \\
\hline & Rural & 214 & 45.6 \\
\hline \multirow[t]{4}{*}{ Marital status } & Single & 65 & 13.9 \\
\hline & Married & 301 & 64.2 \\
\hline & Divorced/separated & 46 & 9.8 \\
\hline & Windowed & 57 & 12.2 \\
\hline \multirow[t]{5}{*}{ Educational level } & Cannot read and write & 249 & 53 \\
\hline & Read and write & 62 & 13.2 \\
\hline & Primary education & 52 & 11.1 \\
\hline & Secondary education & 53 & 11.3 \\
\hline & Collage and above & 53 & 11.3 \\
\hline \multirow[t]{5}{*}{ Occupation } & Government employ & 53 & 11.3 \\
\hline & Merchant & 80 & 17.1 \\
\hline & Farmer & 91 & 19.4 \\
\hline & Housewife & 180 & 38.4 \\
\hline & Others & 65 & 13.9 \\
\hline
\end{tabular}

\section{Clinical characteristics}

Less than three quarters 153 (32.5\%) of the study participants had CHF secondary to IHD; less than one fourth $103(22.1 \%)$ of them had CHF secondary to valvular heart disease, the majority of patients 292 $(62.3 \%)$ had not used health insurance; mean duration of HF was 6.4 years with standard deviation of 4.60. Of the study participants, 251 (53.2\%) were Lasix users (Table 2). 
Table 2

Personal and clinical characteristics of study patients

\begin{tabular}{|c|c|c|c|c|}
\hline Variables & \multicolumn{2}{|l|}{ categories } & Frequency & Percent (\%) \\
\hline \multirow[t]{6}{*}{ Cause of CHF } & \multicolumn{2}{|l|}{ DVHD } & 103 & 22.0 \\
\hline & \multicolumn{2}{|l|}{ IHD } & 154 & 32.8 \\
\hline & \multicolumn{2}{|l|}{ CMP } & 76 & 16.2 \\
\hline & \multicolumn{2}{|l|}{ RHD } & 89 & 19.0 \\
\hline & \multicolumn{2}{|l|}{ Pericardium } & 42 & 9.0 \\
\hline & \multicolumn{2}{|l|}{ others } & 6 & 1.30 \\
\hline \multirow[t]{16}{*}{ Current medication } & \multirow[t]{2}{*}{ Lasix } & yes & 218 & 46.5 \\
\hline & & no & 251 & 53.5 \\
\hline & \multirow[t]{2}{*}{ B-blocker } & yes & 271 & $57 . .8$ \\
\hline & & no & 198 & 42.2 \\
\hline & \multirow[t]{2}{*}{ ACEI/ARB } & yes & 238 & 50.8 \\
\hline & & no & 231 & 49.2 \\
\hline & \multirow[t]{2}{*}{ Digoxin } & yes & 48 & 10.2 \\
\hline & & no & 421 & 89.8 \\
\hline & \multirow[t]{2}{*}{ Warfarin } & yes & 107 & 22.8 \\
\hline & & no & 362 & 77.2 \\
\hline & \multirow[t]{2}{*}{ Aspirin } & yes & 108 & 34.3 \\
\hline & & no & 361 & 65.7 \\
\hline & \multirow[t]{2}{*}{ Atorvastatin } & yes & 121 & 25.8 \\
\hline & & no & 348 & 74.2 \\
\hline & \multirow[t]{2}{*}{ others } & yes & 22 & 4.7 \\
\hline & & no & 447 & 95.3 \\
\hline \multirow[t]{2}{*}{ Utilization of health insurance } & \multicolumn{2}{|l|}{ Yes } & 177 & 37.7 \\
\hline & \multicolumn{2}{|l|}{ No } & 292 & 63.3 \\
\hline
\end{tabular}


To check the internal consistency, the Cronbach's alpha was calculated for each domain of the instrument. All domains of WHOQOL-Brief had high values of Cronbach's alpha $(a>0.7)$. Inter domain correlation showed that, there were statistically significant correlation between domains, there are highly positive correlation between physical health domain and social relation health domain $(r=0.95, p<0.001)$ and as compared with other domain psychological health domain and environmental health domain had relatively weak correlation between them $(r=0.71, p<0.001)$ (Table 3$)$.

Table 3

Internal consistency \& Correlations between the domains of the WHOQOL - Brief

\begin{tabular}{|llllll|}
\hline Domain & Crompach alpha & PH & PSyH & SRH & EH \\
\hline PH & 0.78 & 1.0 & $0.87^{*}$ & $0.95^{*}$ & $0.72^{\star}$ \\
\hline PSyH & 0.72 & & 1.0 & $0.80^{*}$ & $0.71^{*}$ \\
\hline SRH & 0.74 & & & 1.0 & $0.83^{*}$ \\
\hline EH & 0.71 & & & 1.0 \\
\hline $\begin{array}{l}* \text { Correlation is significant at the 0.05 level (two-tailed).PH = physical health, PSyH = Psychological } \\
\text { health, SRH = Social Relation Health, EH = Environmental Health }\end{array}$ & & \\
\hline
\end{tabular}

\section{HRQOL among patients with CHF}

Among four domains of health-related quality of life, respondents scored highest and lowest mean HRQOL score in psychological health domain (50.21 with 15.61 SD) that is moderate HEQOL and physical domain (31.70 with 14.68 SD) that is low HRQOL respectively. The mean score of overall HRQOL of patients with CHF was 41.61 (11.62SD) which was low QOL (Table 4).

Table 4

HRQOL among adults with heart failure patients in UoG Hospital, 2020

\begin{tabular}{|lllrrr|}
\hline Domain & N & Minimum & maximum & Mean & SD \\
\hline Physical health & 469 & 0.00 & 82.14 & 31.70 & 14.68 \\
\hline Psychological health & 469 & 0.00 & 87.50 & 50.21 & 15.61 \\
\hline Social relation & 469 & 0.00 & 100.00 & 46.22 & 14.22 \\
\hline Environmental health & 469 & 6.25 & 87.50 & 38.35 & 14.29 \\
\hline HRQOL & 469 & 13.24 & 78.35 & 41.61 & 11.62 \\
\hline
\end{tabular}

\section{Perceived Health satisfaction and self-rating of HRQOL of patients}

Study participants were asked to give their perception on their quality of life and health satisfaction. Based on their response; about one third 165 (36\%) study participants reported that their quality of life 
was neither good nor poor, while 142 (31\%) of them had poor QOL. Regarding health satisfaction, 202 $(43.10 \%)$ of them were very dissatisfied with their health and only $3.40 \%$ of them were satisfied with their health (Fig. 3 and Fig. 4).

\section{Health-related quality of life and other associated factors}

The final model containing both the structural part (relationships among latent or observed variables) and measurement part (relationship between a latent variable and its indicators or items) is shown in Fig. 4 and Table 5. The fitted model was relatively parsimonious and good fitted with RMSER $=0.04$ and $\mathrm{CFI}=0.96$. Variables like sex, education, type of job, current medication and Utilization of health insurance were excluded from the final model as their contributions were not statistically significant at an alpha level of 0.05 . 
Table 5

The direct, indirect and total effect of socio-demographical and clinical factor on HRQOL domains among patients with CHF attending at UoG, 2020.

Characteristics Direct Effect $(95 \% \mathrm{Cl})$ indirect effect $(95 \% \mathrm{Cl})$ Total Effect $(95 \% \mathrm{Cl})$

DV: dependent variable, * indicates 00 after the decimal and ** indicates 000 after the decimal.

DV: Physical health domain

Age - 0.02(-0.03, -0.02) - -

Residence

Urban 000

Rural $-0.34(-0.45,-0.23)$--

Underlying cause of CHF - 0.07(-0.11, -0.03) - -

DV: Psychological health

Duration CHF - 0.01(-0.02, 0.01) --

Age $-0.02(-0.03,-0.02)-0 .{ }^{*} 1\left(-0.1^{*}, 0.006\right)-0.02(-0.022,-0.012)$

Income 0.01(0. $\left.{ }^{\star \star} 1,0 .{ }^{*} 1\right)$--

Marital status - 0.02()-0.15, -0.02) - -

DV: social relation

Age - 0.01(-0.012, -0.002) - -

Edu 0.08(0.02,0.14) --

DV: Environmental health

Age $-0.01(-0 . * 8,0 . * 2)-$ -

Residence

Urban $0.00-0.00$

Rural - 0.55(-0.08, -0.442) - -

Income $0 . * 1(0 . * 5,0.02)-$ -

Marital status - $0.11(-0.12,-0.04)$ - -

Ocup - 0.04(-0.08, -0.003) --

Hinsurance $0.18(0.04,0.312)$--

DV: HRQOL

Income 0. *1(0. **2,0. $\left.{ }^{\star} 1\right) 0.001\left(0.2^{\star \star}, 0.1^{*}\right) 0.2^{\star \star}\left(0.1^{\star \star}, 0.3^{\star *}\right)$ 
Duration $-0.02(-0.03,-0.9 * \star)-0.01(-0.02,-0.2 *)-0.026(-0.04,0.01)$

In the fitted model, all the path coefficients in the diagram were statistically significant at an alpha level of 0.05 . Accordingly, the model included only six exogenous variables (age, monthly income, current medication, duration of CHF, residency and educational level, four mediator variables (domains of $\mathrm{HRQOL}$ ), and one endogenous variables (HRQOL). six exogenous variables (age, monthly income, current medication, duration of CHF residency and educational level were both directly and indirectly related with $\mathrm{HRQOL}$ via the mediator variables.

This estimated structural equation model indicates that environment health factor had the most substantial causal effect on HRQOL, which was larger than the causal effects of psychological QOL, physical health and social relationship factors. Physical health was statistically significantly associated with the age $(p<0.0001)$, residency $(p<0.0001)$ and underlying cause of $\operatorname{CHF}(p=0.002)$, psychological health domain was significantly associated with duration of $\operatorname{CHF}(P=0.05)$, income $(0.001)$, marital status $(p=0.022)$ and age $(p<0.0001)$, social relation was statistically significantly associated with age $(p<$ $0.0001)$ and education $(p=0.006)$ and Regarding to environmental health domain, it was associated with age $(p=0.03)$, residency $(p<0.0001)$ occupation $(p=0.04)$, income $(p<0.0001)$ and health insurance $(p=$ 0.007) (Fig. 4).

\section{Testing the structural model of the HRQOL of patients with $\mathrm{CHF}$}

\section{Feasibility assessment for the hypothetical model}

We conducted a confirmatory factor analysis of the measurement model in step 1 . The confirmatory factor analysis was performed with demographic factors, social support, disease-related factors, behavioral factors, and HRQQOL, whereas we excluded insignificant variable $(p>0.05)$ from the final model.

\section{Test of the goodness of fit of the hypothetical model}

The results of the analysis of the structural equation model produced using the study variables in the hypothetical model were as follows: goodness of fit for $\chi 2=143.02$

$(\mathrm{P}<0.001, \mathrm{df}=48), \mathrm{GFI}=0.91, \mathrm{RMSEA}=0.04, \mathrm{NFI}=0.91, \mathrm{CFI}=0.95, \mathrm{TLI}=0.93, \mathrm{PGFNI}=0.46$, and $\mathrm{PNFI}=$ 0.44 . All of the GFI indices satisfied the recommended levels.

\section{Effectiveness analysis of the hypothetical model}

The direct, indirect, and total effects of the factors associated with the HRQOL of the patients with CHF are presented in Table 5. The physical health domain had the greatest direct effect on the HRQOL with a score of 0.502. The environmental health factor had a direct effect on the HRQOL with a path coefficient of 0.485 , and psychological health factor had a direct effect on HRQOL with a path coefficient 0.359 . 
Social relation had a direct effect of 0.167 but statistically not significant ( $p$-value $=0.280>0.05$ ) on the HRQOL. Monthly income had direct effect on HRQOL with a path coefficient of 0.01 , and a total effect of 0.02 when added to the indirect effect of environmental health factor (0.001) (Table 5).

\section{Discussion}

In this study, we aimed to construct a hypothetical model and verify the significance of the direct/indirect paths and the goodness of fit of the model under the theoretical assumption that demographic factors, personal related factors, social relation, environmental factor, physical factor, disease-related factors, and behavioral factors, including depression, anxiety, fatigue, pain, sexual activity, and body image, determine the HRQOL of patients with CHF directly and indirectly.

In this study, we found that patients with CHF had lower quality of life in all domains of the WHOQOLBREF especially in environmental health domain (mean score of 38.56) and an overall quality life, which indicate that they know that their heath is poor and affecting their HRQOL. This finding is congruent with other previous study (25). This consistence result might be heart failure is a serious condition and leads to poor quality of life when the condition is not managed with heart failure management's.

From structural equation model, we found that environmental health factors like physical security, financial resources and health care facility had the most substantial causal effect on HRQOL of patients with $\mathrm{CHF}$ with path coefficient of $0.53(95 \% \mathrm{Cl}, 0.32,0.75)$, which was larger than the causal effects psychological health, and physical health, which were in turn larger than the causal effect of social relation domain. This finding is Inconsistent with other study (26). This inconsistency may be due to the research was conducted in developed country and the environmental health may not had larger cause on HRQOL than the other factors. In Environmental health factor physical security, information and skill, and health facility (with loading of 0.80 ) are the highly influcial items on HRQOL as compared with physical environment, financial resource and recreation items (with loading 0.6 ). and transportation and home environment items (with loading 0.58). This result might be, heart failure often leads to the development of physical disabilities that, in turn, can have a detrimental effect on a patient's quality of life.

Our finding demonstrated that, among domains of HRQOL, the physical health domain was most affected domain for HRQOL next to environmental health domain. This finding is In line with a couple of studies (26-28). This consistency could be defensible by CHF has more physical than mental (psychological) manifestations and social relations.

Similarly, psychological health and social relation was the least affected domain among the CHF patients. This finding is in line with other studies that was conducted southwest (29) and northwest (30) Ethiopia among DM patients. This consistence result in social relation and psychological health might be their social-culture that gives support for diseased individuals with DM and CHF. Patients manifest more physically than mentally (psychologically). 
Our results revealed that age had significant association with all domains of HRQOL and had both a positive direct and indirect effect that resulted in a total positive effect on overall HRQOL of CHF patients. Aged 60 and above years had worse mental state, physical health, social relation and environmental health. This finding is lined with previous studies conducted in different research setting $(31,32)$. Based on the knowledge that $\mathrm{CHF}$ incidence increases with age, researchers would anticipate that older patients who experience several limitations such as cognitive impairment, loss of personal autonomy, or anxiety and depression may have poor quality of life(31).

A study conducted in Greece (31) documented that male adults have lower HRQOL in social relation domain than female adult. However, the present study demonstrates that gender have no effect on any domain of HRQOL. Direct comparisons with the findings of other studies are difficult because there are no other comprehensive HRQOL models of patients with CHF from Ethiopia or other African countries. Rural resident was associated with lower HRQOL for an environmental health domain, physical health domain and overall HRQOL with negative path coefficients.

There is a study's (31) which had consistence finding with our study. This congruent finding might be patients' lives in rural area are more likely low in income, the physical environment may not be good, low health care accessibility to get medical treatment and most of them are uneducated so have the low awareness about CHF. Being married was another socio-demographic factor that had a positive effect on environmental health and social relation among CHF patients and this is of course in congruent with other reports (31). This positive effect may be due to, support from others can facilitate recovery from physical illness and enhance the ability to cope with and adapt to the consequences of chronic illnesses.

Also associated with both physical and mental (psychological) health were the years of suffering from the disease (duration of CHF) which may reflect symptoms' severity. Patients often experience loss of functional independence in daily activities such as feeding, dressing, housekeeping, bathing, and walking (33).

It is noteworthy that evaluation is needed of all the changes that take place through years and that may exacerbate HF patients' quality of life such as inability to fulfill their prior role (social, professional, and family), diminished self-esteem, and distorted picture of themselves.

The finding of the present study also showed that income had positive direct effect on physical health, psychological health and environmental health domain of HRQOL. These findings were consistent with previous studies (34). We know that financial situation is are important determinants of health, negatively affecting health outcomes and contributing to health inequities. Patients with low income had low quality of life because most of CHF patients are medical treatment dependence and unable to afford treatment costs.

\section{Strength And Limitation}


In this study, HRQOL was assessed based on standardized tool that is validated for both developed and developing country (WHOQOL_BREF). The current study also used multivariate analysis (SEM) that enables a simultaneous analysis of the impact of multiple independent variables on several dependent variables and the subsequent direct comparison of the respective impact of the independent variables on the dependent variables. This also enables to incorporate the correlation between latent variable and to determine direct, indirect and total effect when mediation effect present simultaneously. However, this study is not without limitations, the data were collected through face to face interview by considering the different educational level of respondents and this might prone to social desirability bias and could overestimate the result. Moreover, the present study has been conducted in single center which limits the generalizability of the finding in Ethiopia; further multicenter studies are needed to address this issue.

\section{Conclusion}

The finding of the study indicated that a moderate to poor HRQOL in the physical dimension, moderately poor overall HRQOL and a moderate to high HRQOL in the psychological health domain. Sociodemographic factors (age, residence and marital status), clinical factor (duration of CHF) were factors associated with HRQOL among CHF. The results indicated that the importance of QOL assessment at appropriate time periods, determining the exact treatment dimensions required, and implementing comprehensive HRQOL promotion programs in all physical, mental, environmental and social relation dimensions.

Based on this result, approaches should be developed or effectively managing physical factors, psychological, and environmental factors to improve the QOL of patients with CHF. Developing and providing intervention programs to enhance social support can lead to improved quality of life for patients, because of the long-term and chronic illness of the patient.

\section{Abbreviations}

AGFI

Adjusted Goodness of Fit Index; AMOS:Analysis of Moment Structures; CFA:Confirmatory Factor Analysis; CFI:Comparative Fit Index, CHF; Chronic Heart Failure, HRQOL:Health Related Quality of Life; NYHA:New York Heart Association; SEM:Structural Equation Modeling; SD:Standard Deviation; UoGCSH:University of Gondar Comprehensive Specialized Hospital; WHO:World Health Organization; WHOQOL:World Health Organization Quality of Life.

\section{Declarations}

\section{Availability of data and materials}

The datasets supporting the conclusions of this article are available upon request to the corresponding author. 


\section{Ethics approval and consent to participate}

Ethical approval was obtained from the Institutional Review Board (IRB) of institute of public health, University of Gondar and a permission letter was obtained from the hospital administrator office. The purpose of the study was well explained and informed consent was secured from study participants.

\section{Consent for publication}

Not applicable.

\section{Competing interests}

The authors declare that they have no competing interests.

\section{Authors' contributions}

GET conceptualized the study, collects the data, analyzed the data and drafted the manuscript. LDG and TYB also participated in designed the study, analyzed the data and critically revised the manuscript. All authors read and approved the final manuscript.

\section{Acknowledgments}

We would like to thank University of Gondar for giving ethical clearance to conduct this research. Additionally we wish to express my sincere thanks and appreciation to data collectors and supervisors for their support during data collection period.

\section{References}

1. Roger VLJCr. Epidemiology of heart failure. 2013;113(6):646-59.

2. Juenger J, Schellberg D, Kraemer S, Haunstetter A, Zugck C, Herzog W, et al. Health related quality of life in patients with congestive heart failure: comparison with other chronic diseases and relation to functional variables. 2002;87(3):235-41.

3. Bui AL, Horwich TB, Fonarow GC. Epidemiology and risk profile of heart failure. Nature Reviews Cardiology. 2011;8(1):30.

4. Group W. Development of the World Health Organization WHOQOL-BREF quality of life assessment. Psychological medicine. 1998;28(3):551-8.

5. Cook C, Cole G, Asaria P, Jabbour R, Francis DPJljoc. The annual global economic burden of heart failure. 2014;171(3):368-76.

6. Zambroski CH, Moser DK, Bhat G, Ziegler CJEJoCN. Impact of symptom prevalence and symptom burden on quality of life in patients with heart failure. 2005;4(3):198-206.

7. Alla F, Briançon S, Guillemin F, Juillière Y, Mertès PM, Villemot JP, et al. Self-rating of quality of life provides additional prognostic information in heart failure. Insights into the EPICAL study. 
2002;4(3):337-43.

8. Angermann CE, Gelbrich G, Störk S, Gunold H, Edelmann F, Wachter R, et al. Effect of escitalopram on all-cause mortality and hospitalization in patients with heart failure and depression: the MOOD-HF randomized clinical trial. 2016;315(24):2683-93.

9. Gupta A, Allen LA, Bhatt DL, Cox M, DeVore AD, Heidenreich PA, et al. Association of the hospital readmissions reduction program implementation with readmission and mortality outcomes in heart failure. 2018;3(1):44-53.

10. Ponikowski P, Voors A, Anker S, Bueno H, Cleland J, Coats A, et al. ESC guidelines for the diagnosis and treatment of acute and chronic heart failure (vol 37, pg 2129, 2016). 2018;39(10).

11. Williams BA, Doddamani S, Troup MA, Mowery AL, Kline CM, Gerringer JA, et al. Agreement between heart failure patients and providers in assessing New York Heart Association functional class. 2017;46(4):293-9.

12. Al-Mohammad A, Mant JJH. The diagnosis and management of chronic heart failure: review following the publication of the NICE guidelines. 2011;97(5):411-6.

13. Rumsfeld JS, Alexander KP, Goff DC Jr, Graham MM, Ho PM, Masoudi FA, et al. Cardiovascular health: the importance of measuring patient-reported health status: a scientific statement from the. American Heart Association. 2013;127(22):2233-49.

14. Anker SD, Agewall S, Borggrefe M, Calvert M, Jaime Caro J, Cowie MR, et al. The importance of patient-reported outcomes: a call for their comprehensive integration in cardiovascular clinical trials. 2014;35(30):2001-9.

15. McDonald MA, Ashley EA, Fedak PW, Hawkins N, Januzzi JL, McMurray JJ, et al. Mind the gap: current challenges and future state of heart failure care. 2017;33(11):1434-49.

16. Hunt SA, Baker DW, Chin MH, Cinquegrani MP, Feldman AM, Francis GS, et al. ACC/AHA guidelines for the evaluation and management of chronic heart failure in the adult: executive summary: a report of the American College of Cardiology/American Heart Association task force on practice guidelines (committee to revise the 1995 guidelines for the evaluation and management of heart failure) developed in collaboration with the International Society for Heart and Lung Transplantation endorsed by the Heart Failure Society of America. 2001;38(7):2101-13.

17. Gasperoni F, leva F, Barbati G, Scagnetto A, lorio A, Sinagra G, et al. Multi-state modelling of heart failure care path: A population-based investigation from Italy. 2017;12(6):e0179176.

18. Brunner-La Rocca H-P, Rickenbacher P, Muzzarelli S, Schindler R, Maeder MT, Jeker U, et al. End-of-life preferences of elderly patients with chronic heart failure. 2011;33(6):752-9.

19. Jaarsma T, Halfens R, Abu-Saad HH, Dracup K, Stappers J, Van Ree JJEJoHF. Quality of life in older patients with systolic and diastolic heart failure. 1999;1(2):151-60.

20. Thommasen H, Berkowitz J, Thommasen AT, Michalos AC. Understanding relationships between diabetes mellitus and health-related quality of life in a rural community. 2005.

21. Yancy CW, Jessup M, Bozkurt B, Butler J, Casey DE, Drazner MH, et al. 2013 ACCF/AHA guideline for the management of heart failure: a report of the American College of Cardiology 
Foundation/American Heart Association Task Force on Practice Guidelines. 2013;62(16):e147-e239.

22. Dattalo P, Thyer BA, Littell JH, Corcoran J, Pillai V, Danto EA, et al. Structural Equation Modeling Pocket Guides to Social Work Research Methods Structural Equation Modeling Structural Equation Modeling.

23. Lopes ACJRSBCM. 25 anos representando os clínicos brasileiros. 2014;12(1).

24. Matsunaga M. Item parceling in structural equation modeling: A primer. Communication Methods Measures. 2008;2(4):260-93.

25. AbuRuz ME, Alaloul F, Saifan A, Masa'Deh R, Abusalem S. Quality of life for Saudi patients with heart failure: a cross-sectional correlational study. Global journal of health science. 2016;8(3):49.

26. Lee S-Y, Song X-Y, Skevington S, Hao Y-T. Application of structural equation models to quality of life. Structural equation modeling. 2005;12(3):435-53.

27. Mijinyawa M, Yusuf S, Gambo M, Saidu H, Dalhatu A. Health Related Quality of Life among Patients with Ischaemic Heart Disease in Kano, Nigeria. J Vasc Med Surg. 2016;4(282):2.

28. Boczor S, Daubmann A, Eisele M, Blozik E, Scherer M. Quality of life assessment in patients with heart failure: validity of the German version of the generic EQ-5D-5L ${ }^{\mathrm{TM}}$. BMC Public Health. 2019;19(1):1464.

29. Muze M, Hailu E, Woldemichael K, Fekecha B. Health related quality of life and its associated factors among diabetic patients attending diabetes clinic in Jimma university teaching hospital, Ethiopia, 2014. J Diabetes Metab. 2017;8(751):2.

30. Reba K, Argaw Z, Walle B, Gutema H. Health-related quality of life of patients with diagnosed type 2 diabetes in Felege Hiwot Referral Hospital, North West Ethiopia: a cross-sectional study. BMC Res Notes. 2018;11(1):544.

31. Audi G, Korologou A, Koutelekos I, Vasilopoulos G, Karakostas K, Makrygianaki K, et al. Factors affecting health related quality of life in hospitalized patients with heart failure. Cardiology research and practice. 2017;2017.

32. Gallagher AM, Lucas R, Cowie MR. Assessing health-related quality of life in heart failure patients attending an outpatient clinic: a pragmatic approach. ESC heart failure. 2019;6(1):3-9.

33. Dunlay SM, Manemann SM, Chamberlain AM, Cheville AL, Jiang R, Weston SA, et al. Activities of daily living and outcomes in heart failure. Circulation: Heart Failure. 2015;8(2):261-7.

34. Kang K. Health-related quality of life in patients with myocardial infarction: trends and predictors 2018.

\section{Figures}




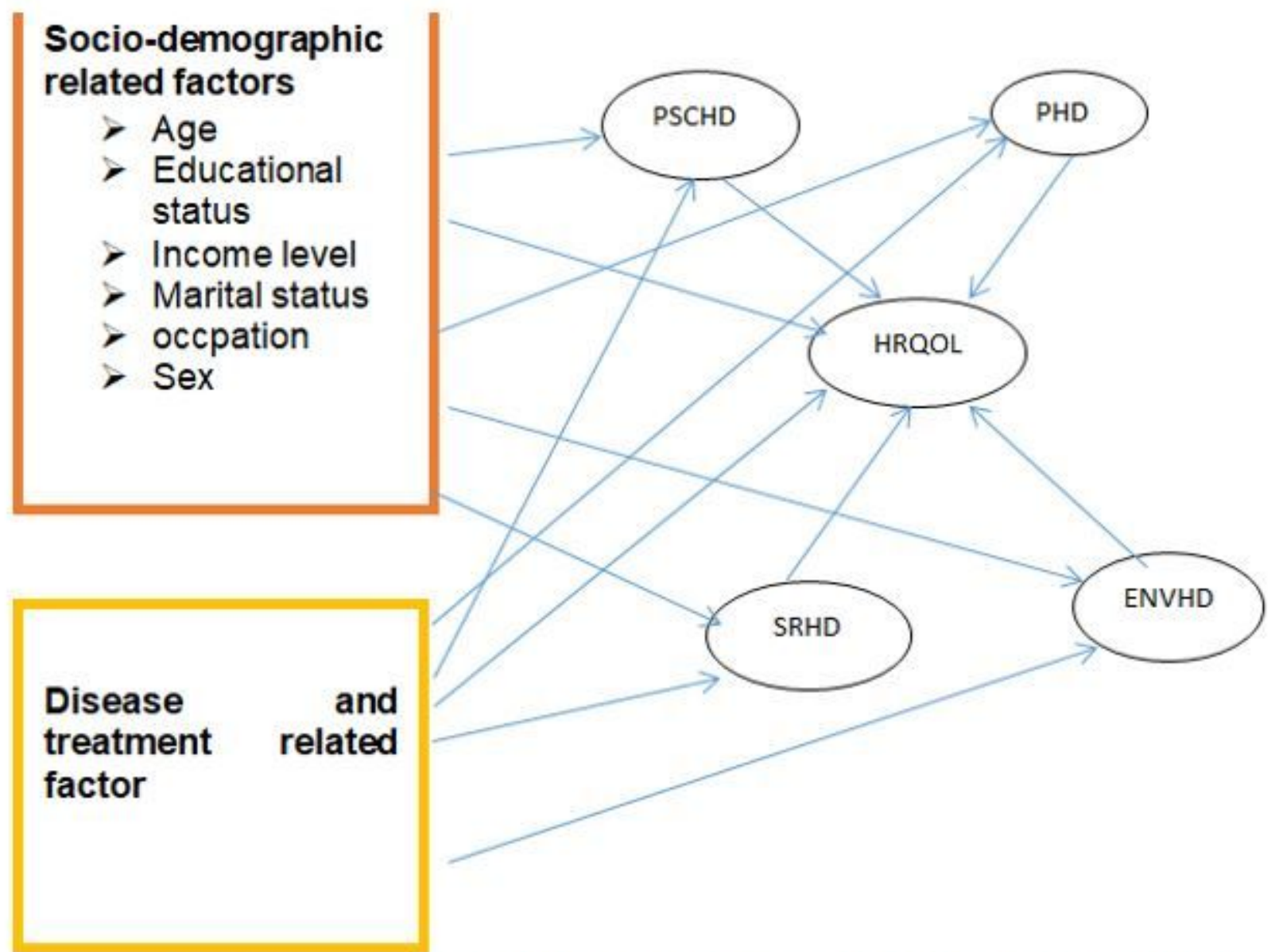

Figure 1 Hypothesized model for factors associated with health Related QLuality of Life of heart failure patients; single headed arrows show direction of effect; double headed arrow shows correlation on factors.

Where, phd= physical health, pshd = psychological health domain, SR= social relationship, ENV = environment health domain

Figure 1

Figure 1 


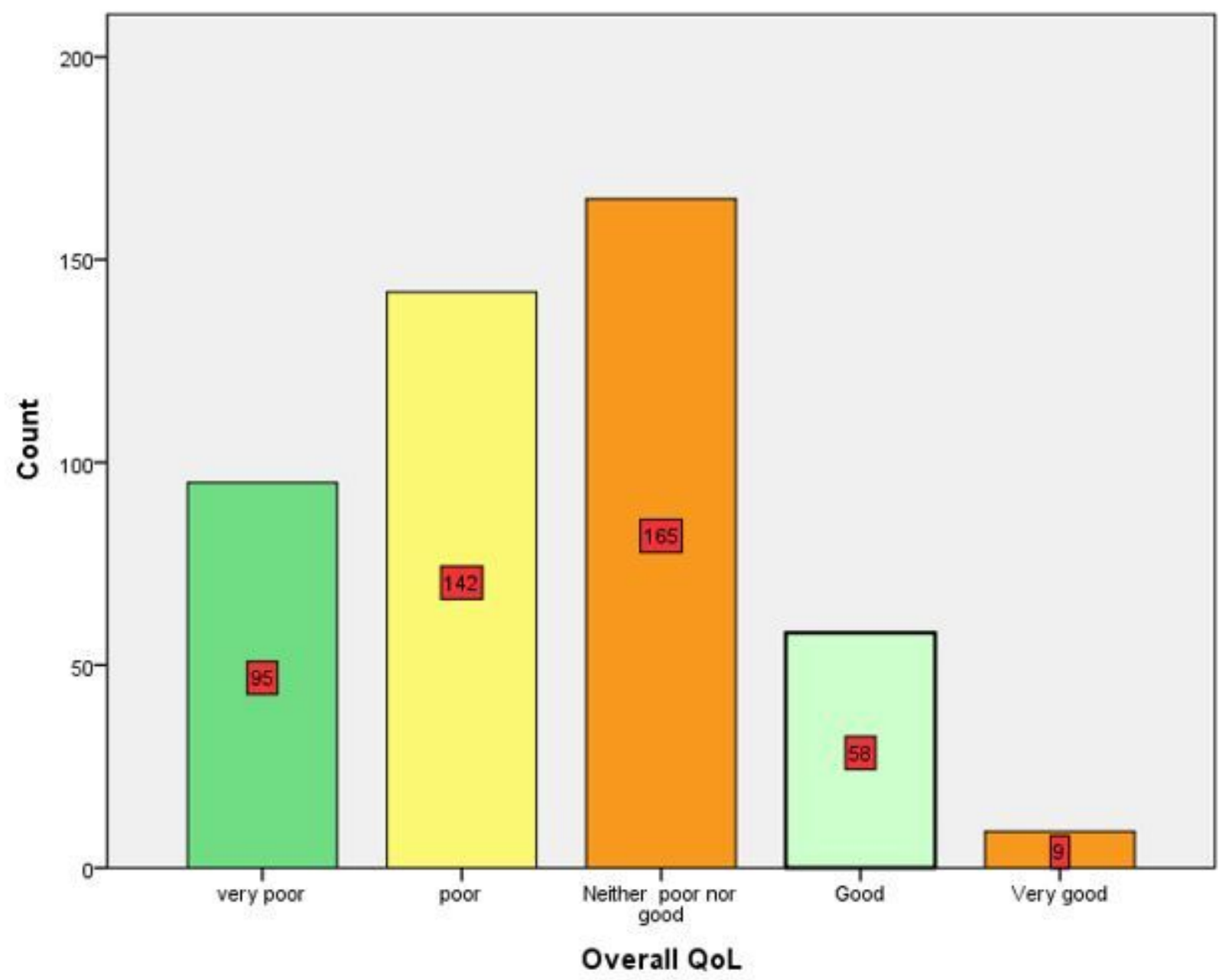

Figure 2

Perceived self-rated QOL of chronic heart failure patients attending at University of Gondar Hospital,2020. 


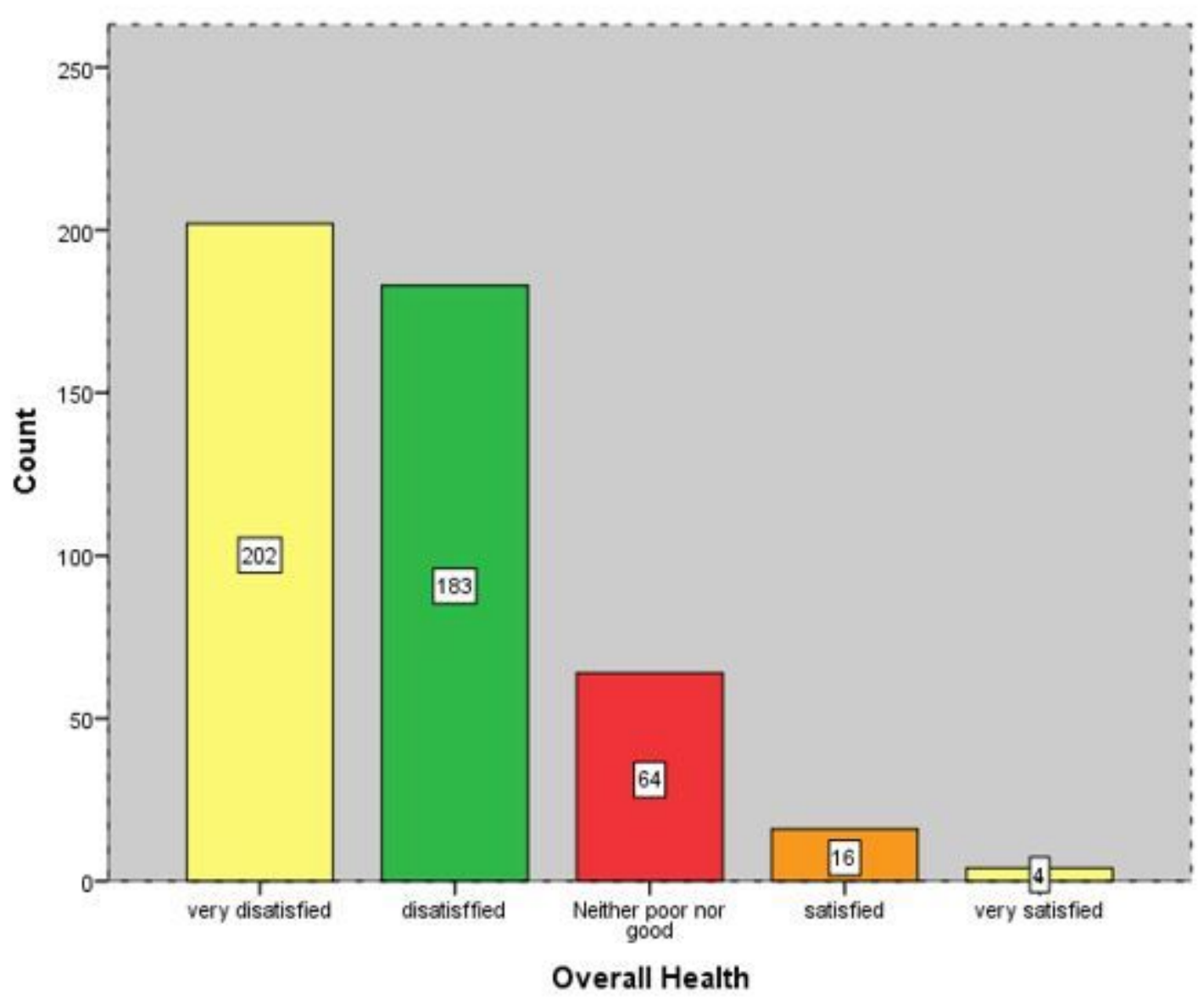

Figure 3

Perceived self-rated health satisfaction of chronic heart failure patients attending at University of Gondar Hospital,2020 


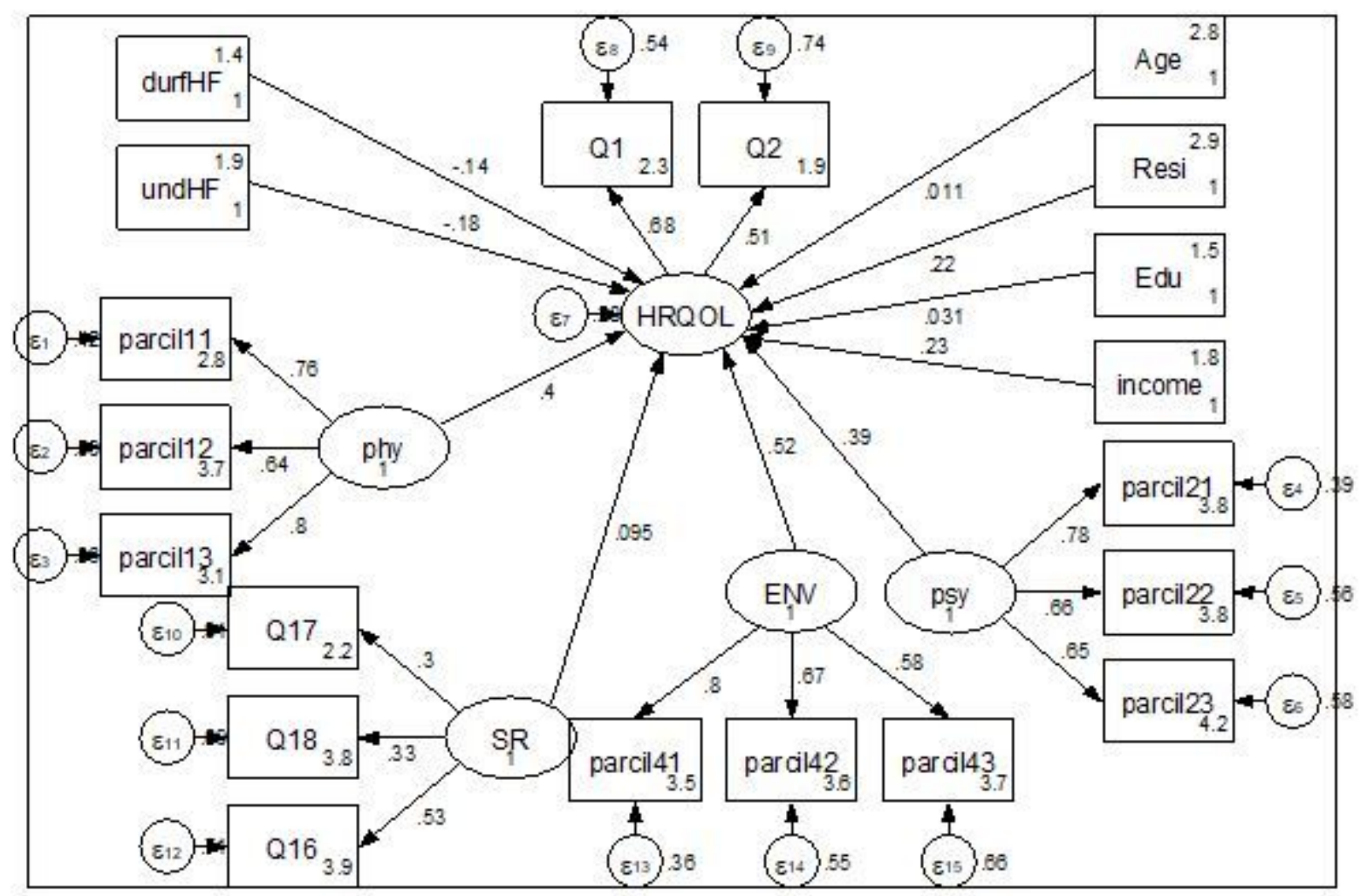

Figure 4

SEM for factor associated with HRQOL among patients with CHF attending at UoGCSH. Where, phy= physical health domain, ENV = environmental health domain, $\mathrm{SR}=$ social relation domain, psy = psychological health domain, parcil11 = average of Q3 and Q5, parcil12 = average of Q6 and 7, parcil13 = average of Q4, Q8 and Q9, parcil21 = average of Q13 and Q15, parcil22 = average of Q10 and Q12,parcil23 = average of Q11 and Q14, parcil41 = average of Q19,Q22 and Q26, parcil42 = average of Q21, Q23 and Q25, parcil43 =average of Q20 and Q24, Resi = Residents of patients, Edu = educational level of patients durfHF = duration of heart failure on patients and undHF = underlying cause for $\mathrm{CHF}$. 